\title{
Accessing and engaging with video streams for educational purposes: experiences, issues and concerns
}

\author{
Maggie Bracher, Richard Collier, Roger Ottewill* and \\ Kerry Shephard \\ University of Southampton, UK
}

\begin{abstract}
Video streaming has the potential to offer tutors a more flexible and accessible means of incorporating moving images into learning resources for their students than conventional video. Consideration is given to this assertion by drawing upon the experiences of staff and evidence from students at the University of Southampton in the use of a video, Back Care for Health Professionals, before and after it was streamed. The resulting case study highlights various issues and concerns, both logistical and pedagogic. These include ease of access, the form and frequency of guidance with respect to technical matters, the use of multiple channels of communication to convey key messages about the availability and value of the video, and the provision of demonstrations or 'tasters'. In other words, what some might regard as the 'softer' aspects of technological developments should receive at least as much attention as the 'harder'.
\end{abstract}

\section{Introduction}

In recent years, one of the most significant advances in the provision of moving images as an educational resource has been the advent of video streaming. The Joint Information Systems Committee (JISC) has defined video streaming as:

Transmission of moving images over the internet in compressed form as a continuous stream. A recipient equipped with suitable 'player' software can decompress and view the images in real time - as distinct from the alternative of waiting while a video file is downloaded and viewing subsequently. (JISC, 2004)

Recognition of the potential of streaming in educational settings led to JISC funding two major projects in this field: Click and Go Video (2002) and LIFESIGN (2002).

\footnotetext{
*Correspondingauthor. CentreforLearningandTeaching, UniversityofSouthampton, Highfield, Southampton SO17 1BJ, UK. Email: rmo2@soton.ac.uk
} 
Both projects reached similar conclusions regarding the benefits of streaming. The Click and Go project team expressed them in the following terms:

The advantage of streaming is that it can enable easier and more responsive on-demand access to multimedia resources. Perhaps even more exciting is the possibility of integrating video and audio with other web-based resources, for example communication and quiz tools. (Thornhill et al., 2002, p. 5)

Likewise, members of the LIFESIGN project team argued that one of the reasons for investing time and money in streaming existing educational videos is to enhance their flexibility and value as a learning resource. They also claimed that streamed video can be accessed more readily and be more effectively 'embedded ... in the student learning environment' (Shephard et al., 2003, p. 16) than conventional video. Another more recent development in this field is the Digital Video Applications research project, which is based in the Open University Library. One of its aims is to explore the use of video streams in the context of resource-based learning and their pedagogical impact (Digital Video Applications, 2004). Meanwhile, Shephard (2003) has established a case for more formal evaluation and communication of educational processes involving streaming, and identified elements of a research agenda that could further develop the application of streaming technology in education.

In this paper, the authors report on their experiences of using an educational video, Back Care for Health Professionals, before and after it was streamed, with particular attention being paid to the latter. Back Care for Health Professionals was produced by the University of Southampton, in conjunction with the National Back Pain Association, in 1998 and comprises two videos. The first highlights the need to give continuous attention to back care (i.e. on a 24-hour basis) and the second demonstrates safe moving and handling practices in a hospital environment. Each video is divided into a number of parts. To supplement the conventional video, a written guide explains its purpose, suggests a possible format for running a course with the material and contains text suitable for photocopying onto overhead transparencies. The guide was adapted by the University of Southampton from one published jointly by the National Back Pain Association and Royal College of Nursing in 1998. The video was used in the conventional format until the summer of 2002.

The re-purposing of the video for streaming purposes was carried out under the auspices of the LIFESIGN project during the late spring of 2002, with the video stream being available from the end of June 2002 (Shephard et al., 2003). The stream is incorporated into a Web-based learning resource, which provides supporting text linked to each section of the video. The purpose of the text is to assist learners in engaging with the content of the video stream. Since becoming available there have been a number of opportunities for investigating different aspects of its use. The case study presented in this paper serves as a contribution to the ongoing debate concerning access to and engagement with video streams, particularly in the context of blended learning. The paper is divided into four parts. The first discusses the experience of using the back care video as a learning resource prior to its streaming. In the second part, an assessment is made of two attempts to facilitate engagement with 
the streamed video by participants on a moving and handling post-registration foundation course in 2002. The third part focuses on usage of the video stream by first-year allied health profession undergraduates in 2002/03 and 2003/04. In the final part, issues and concerns are highlighted. Ethical approval for collecting student evaluation data regarding the video streaming was secured from the internal ethics committee of the relevant school of the university. Approval, however, did not extend to collecting student evaluations of the conventional use of the video, and consequently in this part of the paper reliance is placed primarily on the impressions of the tutors concerned. Although this has resulted in a narrowing of the empirical base, it does highlight the need to work within, and to respect, the ethical conventions of different disciplines, in this case those relating to health care, when undertaking educational research.

Throughout the paper, the authors combine critical reflection (Clarke \& Croft, 1998) on, and informed judgement of, the efficacy of video streaming in general, and Back Care for Health Professionals in particular, with evidence from various sources, including students. The overall conclusion is that if the potential of video streaming as a learning resource is to be maximised, then attention has to be given to issues of: (i) access, and (ii) accessing and engagement (Shephard et al., 2003; Fill \& Ottewill, 2005).

\section{Evaluation of conventional use of the video}

From the point of view of tutors, prior to its streaming Back Care for Health Professionals was seen as making an important contribution to the learning of both undergraduates and postgraduates. This was because back care and moving and handling skills have long been key components of the first-year curriculum for allied health professions and for specialist post-registration courses. Thus, tutors considered the video to be an essential learning resource rather than an optional extra. The importance of the video was stressed to students, by showing them part of the video in class and encouraging them to borrow a copy from a member of staff, which they could then view in their own time. Judging by the number of requests for the video, many did so either on their own or in small groups. By this means, they were able to reinforce their learning and prepare for a practical examination, in which they were required to demonstrate two handling manoeuvres, paying particular attention to client safety and also to posture and personal wellbeing. Since they had no advance warning of which manoeuvres they had to demonstrate, they needed to be competent in them all and the video served to remind them of what was involved.

On the whole, tutors felt that the arrangements for providing students with access to the video worked reasonably well. Indeed, students appeared to gain enjoyment and satisfaction from using it as a means of preparing for their examination. Tutors, however, were by no means complacent. From student surveys (the detailed results of which have to remain confidential for ethical reasons) and personal observation they were aware that some students did not follow their advice and made no use of 
the video, while a number of those who wanted to view it found it difficult to get hold of a copy. They also recognised that a conventional video was in some respects a relatively blunt and inflexible learning resource, and one that did not necessarily encourage engagement. Indeed, Laurillard (2002) describes video as, primarily, a narrative medium that does not, easily and on its own, support active learning unless delivered through a computer. 'In this mode it inherits expectations of interactivity' (Laurillard, 2002, p. 105). By taking advantage of streaming technology tutors hoped to reduce these negative attributes. More positively, they hoped to improve access and facilitate 'richer and deeper learning' and greater student-centredness (Thornhill et al., 2002, p. 7).

\section{Evaluation of postgraduate use of streamed video: 2002}

The first group of students to whom it was hoped to make the video stream available were those enrolled on a post-registration foundation moving and handling course, which started in July 2002. The basic format of this short course is a one-week intensive study and practical programme, for health care professionals, held in Southampton. Following this there is a period for reflecting on what has been learnt, undertaking assessment tasks, revising for a practical examination and producing a written assignment. The latter is undertaken in the students' own practices and/or local higher education/further education (HE/FE) institutions. Since students attend the course from all over the country it was hoped that they would be able to access the video in their home area, having been given a taster of the video during their time at Southampton.

It was not possible, however, for students to access the streams in their own homes, even if they had broadband. This was because, in taking account of copyright restrictions, access to LIFESIGN project streams was limited to the internet protocol (IP) addresses of computers in $\mathrm{HE} / \mathrm{FE}$ institutions. Thus, the best alternative was to secure access for them at a local $\mathrm{HE} / \mathrm{FE}$ institution. Of the 24 students on the course, about 10 expressed interest in accessing the video by this means.

In the event, this proved to be impossible to arrange for most students. A major hurdle was that there was not, at the time, a computing and information technology equivalent of the UK Libraries Plus Scheme. This meant that there were no 'reciprocal arrangements' whereby students could use facilities in their home locality by virtue of being registered with an $\mathrm{HE} / \mathrm{FE}$ institution elsewhere. Consequently, access had to be requested on a 'case by case' basis. Although most requests secured a positive response, this was clearly a time-consuming process. Moreover, the numbers involved were very small and the case for access could be justified in terms of assisting the LIFESIGN project. Requests for larger numbers of students that could not be linked to a project of this kind might well have been rejected. Since then, following a pilot project that ran from 2002 to 2003, a UK Computing Plus Scheme has been introduced. At the time of writing, however, the number of libraries participating in the scheme is very small by comparison with those in the UK Libraries Plus Scheme (UK Libraries Plus, 2005). 
Difficulties over access also arose when it was discovered that some HE/FE institutions were not included in LIFESIGN's IP address inventory. At the same time, where it was possible to overcome the previous two difficulties, it was sometimes found that the IT equipment did not have sound cards and/or Windows Media Player. As a result, the video stream could not be accessed.

While it can be argued that at least some of these difficulties could have been anticipated, it is often the case that, without the benefit of hindsight, certain assumptions will be made that ultimately prove to be incorrect. As a result of the unanticipated hurdles, none of the students on this course were able to make use of the video streams, although in some cases the conventional video was available as an alternative. In the circumstances, another attempt at evaluating the video stream was clearly essential.

In view of the problems encountered with the July cohort, for the next postregistration course held in October 2002 it was decided to encourage students to access the video stream while they were in Southampton, using computers in the host school for this purpose. Out of 24 students, 13 completed an evaluation questionnaire when they returned for their practical examination. In securing ethical clearance for this research one of the conditions was that students were under no obligation to provide evaluative data. Hence the response was lower than might otherwise have been the case. Of those who did complete the questionnaire, seven had made further use of the video following an introductory session. Data from these students are summarised in Table 1.

These data together with comments from students who had and had not used the video, in response to an open-ended invitation in the questionnaire, present a mixed picture. Some comments were very positive:

Good video, and for initial revising. I would recommend this video to start students revision off.

Others were more critical:

The video needs more updating.

Table 1. Responses from students who had made use of the video in 2002

\begin{tabular}{lccc}
\hline Statement & $\begin{array}{c}\text { Strongly agree/ } \\
\text { agree }\end{array}$ & Neutral & $\begin{array}{c}\text { Strongly disagree/ } \\
\text { disagree }\end{array}$ \\
\hline $\begin{array}{l}\text { I found it difficult to access the video stream } \\
\text { The supporting text helped me to get more } \\
\text { from viewing the stream }\end{array}$ & 2 & 3 & 2 \\
$\begin{array}{l}\text { I enjoyed using the video stream } \\
\begin{array}{l}\text { Idonot think the video enhanced mylearning } \\
\text { about back care }\end{array}\end{array}$ & 2 & 4 & 2 \\
$\begin{array}{l}\text { The video played a significant part in my } \\
\text { revision for the practical examination }\end{array}$ & 1 & 2 & 3 \\
\hline
\end{tabular}

Note: Because of the small numbers involved percentages have not been calculated. 
The video was only focused towards a hospital environment therefore came across [as] very unrealistic.

Some felt that access was the most significant issue, and a number wanted this via the Internet. Clearly, if students are to be encouraged to use video streams from 'remote locations', then the development of more flexible approaches to access are critical. This, of course, often has to be balanced against the need to restrict access to bona fide users.

Given the very small numbers involved and the fact that this is a case study, it is clearly important not to claim too much for these findings. That said, the findings do point to the need for further exploration of issues of access and of student attitudes towards moving images as a means of facilitating their learning and the extent to which the claims of those promoting video streaming are justified.

\section{Evaluation of undergraduate use of streamed video: 2002/03 and 2003/04 cohorts}

Two cohorts of allied health profession undergraduates served as the research subjects for the findings reported in this part of the paper. They were made aware of the video stream in a number of ways. First, it was brought to their attention during the initial lecture of the relevant module. Second, they were reminded during practical sessions throughout the module. Finally, they were given instructions regarding access to the video stream in their handbook. It was felt that this would be sufficient to maximise student use of the video now that it had been streamed.

For the 2002/03 cohort, evaluation of the video stream formed part of the general course evaluation. Questions relating to the back care video stream were attached to the end of the course evaluation questionnaire. This was distributed to students in March 2003, a couple of months before their examination.

Conducting the evaluation in this way had certain advantages in that it avoided over-surveying the students and was a more cost-effective option than carrying out a separate survey. However, it did mean that the effective collection of data was dependent on factors that were not directly connected with the back care video. Moreover, ethical considerations meant that there was no obligation on students to complete that part of the questionnaire, which covered the video stream. In the event, the results were very disappointing with data being obtained from only 25 students out of a total of 147 (a response rate of 17\%). Because the amount of data collected was limited in scope, it was decided to repeat the exercise with the 2003/04 cohort. This time the back care video stream was evaluated separately from the course as a whole. In addition, the questionnaire was distributed, completed and collected during a timetabled class in March 2004. It was also kept as short as possible and no attempt was made to gather demographic data from the respondents in order to ensure as much anonymity as possible, something to which the school's ethics committee attached considerable importance.

The changes made for the 2003/04 cohort resulted in a far higher response rate of $79 \%$, with 119 students out of 150 providing data. However, in each case the 
percentage of respondents who had actually accessed the video steam at the time the survey was conducted was very similar, $24 \%$ in 2003 (i.e. five respondents) and $26 \%$ in 2004 (i.e. 31 respondents). It is very likely that a much larger percentage actually viewed the video stream prior to their practical examination. Indeed, as illustrated later, one or two of the students indicated in their responses to the open-ended request for comments that the questionnaire itself increased the likelihood that they would access the stream. In the circumstances it would have been useful to gather follow-up data once the examinations were over, but this was extremely difficult to organise since students immediately departed for their placements. At the same time, ethical considerations precluded the possibility of seeking to establish whether the performance in the practical examination of those students who had accessed the stream was better than those who had not.

Notwithstanding the shortcomings of the data collection methods employed and the ethical constraints, the findings do offer some interesting insights into student attitudes towards, and engagement with, a learning resource of this kind and offer some pointers as to what needs to be done to raise the profile of the back care video stream. Of those respondents from the 2002/03 cohort who had viewed the stream, the amount of time devoted to this activity varied from as little as $30-45$ minutes to as much as three hours. It is not without significance, perhaps, that the student who spent the most time viewing the video also had the most favourable views as to its value. In the case of the 2003/04 cohort, of those reporting that they had accessed the stream, the amount of time spent viewing it varied from 5 to 60 minutes (three respondents did not indicate the time spent viewing the video). The median viewing time was approximately 30 minutes.

The responses to a series of evaluative statements of those who had already viewed the stream are presented in Table 2 . While it is important not to read too much into the comparisons, given the very small number of respondents in 2003, the patterns that emerge are relatively similar and reasonably encouraging.

Of those who responded, the majority enjoyed using the video stream and thought that it had enhanced their learning about back care. Against this, however, must be set the fact that, although the percentage declined between 2002/03 and 2003/04, a minority still found it difficult to access the stream. Moreover, many respondents were somewhat equivocal about the supporting text, which suggests that some attention should be given to this aspect. Since the text was produced by tutors, perhaps using a student focus group to obtain some insights into what is felt to be most appropriate and beneficial from a user perspective would help to realise one of the claimed benefits of streaming, namely the blending of streams with other media (Thornhill et al., 2002).

Those who had not yet accessed the video were asked to indicate, by means of an open-ended question, the reason(s) why they had not done so. Not surprisingly, there were a variety of responses to this question, with some respondents providing multiple reasons. On the basis of these, students can be arranged along a continuum from those who claimed they did not know about the video stream to those who did and were about to use it. Thus, there were those who: 
Table 2. Responses from those members of the 2002/03 and 2003/04 cohorts who had accessed the video stream

\begin{tabular}{|c|c|c|c|c|c|c|}
\hline \multirow[b]{2}{*}{ Statement } & \multicolumn{2}{|c|}{$\begin{array}{l}\text { Strongly agree/ } \\
\text { agree }\end{array}$} & \multicolumn{2}{|c|}{ Neutral } & \multicolumn{2}{|c|}{$\begin{array}{l}\text { Disagree/strongly } \\
\text { disagree }\end{array}$} \\
\hline & $2002 / 03$ & $2003 / 04$ & $2002 / 03$ & $2003 / 04$ & $2002 / 03$ & $2003 / 04$ \\
\hline $\begin{array}{l}\text { I found it difficult to access the } \\
\text { video stream }\end{array}$ & 2 & 7 & 0 & 2 & 3 & 22 \\
\hline $\begin{array}{l}\text { The supporting text helped me } \\
\text { to get more from viewing the } \\
\text { stream }\end{array}$ & 2 & 15 & 2 & 13 & 0 & 3 \\
\hline $\begin{array}{l}\text { I enjoyed using the video } \\
\text { stream }\end{array}$ & 3 & 20 & 1 & 9 & 0 & 2 \\
\hline $\begin{array}{l}\text { I do not think the video } \\
\text { enhanced my learning about } \\
\text { back care }\end{array}$ & 0 & 1 & 0 & 4 & 4 & 26 \\
\hline
\end{tabular}

- did not remember being told about the video stream;

- had forgotten about the stream;

- were not aware of its relevance;

- were unsure how to access the stream;

- had sought unsuccessfully to access the stream;

- had not had the time (the most 'popular' reason);

- had other priorities;

- did not consider the need to do so was sufficiently pressing; and

- were planning to view the stream in the near future.

A selection of the fuller responses, which are indicative of the variety of reasons for failure to access the stream by the time the survey was conducted, are presented in Table 3.

Of the quotations in Table 3, a clue as to why some students were not aware of the video comes from one of the 2002/03 cohort who states (honestly and disarmingly!) that he/she 'probably wasn't listening at the start of the module'. This suggests that where resources are deemed to be of particular importance for students, more novel and varied ways of bringing them to their attention are required.

One particular message that seems to come through is that there was some misunderstanding and confusion over where the video could be accessed. From a number of comments it would seem that students were under the impression that it was a conventional video and that a video cassette recorder was required. In addition, quite a number referred to the difficulty/impossibility of accessing it from home, since their computers did not have the necessary software or Internet connections. They did not seem to realise that the video stream was a resource that could only used at the university. This suggests that students require further and 
Table 3. Selection of reasons why video stream not accessed

\begin{tabular}{ll}
\hline Cohort & Reason \\
\hline 2002/03 & I don't actually remember being told about the video stream and there weren't any \\
& reminders. Also I don't actually have the facilities to watch a video \\
& Need to get home — childcare when not necessary to be at uni. Have video at home \\
+ notes. May still look at video stream—need to investigate \\
Wasn't aware of it until last week (probably wasn't listening at start of module) \\
Haven't found time yet-everytime I've seen the link I've been busy doing \\
something else \\
Honestly I completely forgot about the back care video, and actually can't \\
remember being told about it. Also don't actually know how to use the video \\
stream, can't remember being told how to use it \\
It has not been a priority to look at it yet. I was aware, but was leaving it until other \\
work/assessments were completed. I formed the opinion that it is something we \\
could look at if we were interested (i.e. not a key part of our learning) \\
I think I've seen the link for it on the website, but I wasn't aware that it was relevant \\
to us; I didn't know that it was so closely linked to moving and handling in the first \\
year. I thought it was especially for third years, or something like that anyway \\
I have seen a similar video before on this subject, prior to coming to university, as \\
well as completing a research project on the subject. I have been busy preparing for \\
examinations + assignments \\
I don't think I am organised enough to have used this system this early enough \\
before the examination \\
Ihave had so much work to do and therefore had very little time to make use of the \\
video. Also, with the revision I am concentrating on at the moment it hasn't been \\
relevant
\end{tabular}

possibly clearer guidance on both how and where video streams can currently be accessed.

Respondents who had not accessed the video stream were also asked a second open-ended question to find out what would have been needed for them to have done so. Apart from 'more time', to which a majority referred, and having computers with Internet connections, there were broadly three suggestions.

The first suggestion can be succinctly expressed as 'reminders'. It would seem that for many students simply having information about a learning resource in one or two forms is not sufficient. If something is particularly important for their learning then, as already indicated, messages need to be constantly reinforced since they are in competition with many other claims on student attention spans. Associated with this is the need for instructions regarding access to be kept constantly in the foreground.

Second, a number of respondents suggested that if the video was that important it should be shown, in full or in part, in class time. In the words of two students:

I will definitely make use of it, but need 'encouragement' to watch it in my own time. I will be more than happy to watch it in lecture times, if it is that important that we watch it. 
I do intend to watch it but if it was either shown in lectures or made compulsory then it would be made use of.

This, of course, conflicts with the notion of self-managed and/or independent learning, but it seems to be a particular issue for some students. That said, quite a number recognised the video's value for revision purposes and, as previously mentioned, indicated that they would definitely be accessing it in the near future.

A third suggestion, which was not always articulated as clearly as others, but nonetheless should not be disregarded, concerns the video's usefulness. A few respondents implied that if they were going to devote some of their study time to viewing the stream, they needed to be assured that it would be time well spent.

To end on a positive note, as one respondent commented:

I'm afraid I wasn't aware of the video stream, however this questionnaire has drawn it to my attention, and I shall make sure I make use of this information.

Thus, at the very least, the evaluative research provided useful 'publicity' for the back care video stream. Whether or not it actually increased the number of students viewing the video, however, is not known.

\section{Issues and concerns}

What these findings illustrate, above all else, is that streaming must not be seen as an end in itself. If it is to be used effectively to enhance student learning, careful consideration has to be given to both logistical and pedagogic issues. Moreover, it is desirable to keep the situation under constant review and to recognise that as much, if not more, can be learnt from what might be considered failures as successes.

\section{Access}

From a logistical point of view the key concern is ease of access. Unless students can access video streams more easily than conventional videos, their potential as a learning resource is unlikely to be realised. Ideally this means access at home, but until broadband is the norm access via a public workstation or alternatively providing students with the video streams and supporting material on CD-roms are the most feasible options. To facilitate the former, but still restrict access to bona fide users, a more flexible mechanism than the IP address system, such as an Athens password, is required. In addition, there is a pressing need for more libraries to join the UK Computing Plus Scheme. Even for campus-based students, building time into their work schedules for accessing videos has to be encouraged and the message reinforced at regular intervals.

\section{Engagement}

However, overcoming problems of access to video streams, for which tutors and educational institutions must accept primary responsibility, is only a necessary, not a 
sufficient, condition for effective learning from such streams. In other words, simply ensuring that students can view the video does not guarantee that they will do so, access is not the same as accessing, or if they do access it that their learning will be enhanced. Equal attention needs to be given to motivational and pedagogic issues. Several published case studies emphasise the fact that the impact of video streams as learning resources can be limited by students' enthusiasm to use them. Limited student motivation to use online resources was highlighted by Zenios (2002) as a key factor, and Green et al. (2003) found that streamed video resources did not appeal to, or were not adequately accessible by, a significant proportion of student nurses. In the case of the back care video, the most important of the motivational issues relate to the:

- accuracy and contemporaneity of the content;

- availability of electronic guides/tutors by the side;

- provision of formative feedback; and

- means of confirming and celebrating learning.

As further experience is gained in the use of the back care video stream to support learning, particularly with large numbers of undergraduates for whom access is less of an issue, it is intended to fine tune the contributions it makes to learning. From the evidence gathered so far, it is likely that various versions of the supporting text will emerge each targeted at a particular group of learners (e.g. undergraduate/postregistration, nurses/occupational therapists/physiotherapists) and addressing their specific needs. The flexibility offered by video steaming makes this a feasible prospect. Another facility that will be of considerable benefit for tutors, as it becomes available, is the ability to 'cut and paste' from videos and to construct their own 'play-lists'. This will enable them to tailor images to the particular needs of their students as they have traditionally been able to do with written material.

\section{Conclusion}

With the increasing availability of streamed videos as learning resources, it is incumbent upon educationalists to ensure that they give due attention to not only the intrinsic quality of their content, but also what is required to maximise their contribution to learning. What the research reported in this paper has shown is that if the effort expended in producing the resource is to pay dividends, then issues of access and engagement must not be ignored. They will not take care of themselves. Indeed, using streaming media successfully will also require both lecturers and students to change their traditional roles and expectations. As suggested elsewhere (Shephard, 2003), in some respects students will need to become more 'independent', but teaching staff will need to work less independently as they embrace the practicalities of teamwork. Delivery of resources as demanding as streaming video requires a significant number of professionals to work together, as a team.

Here, the importance of having a proactive, collaborative strategy cannot be overstated. Many elements of such a strategy are evident in both the current practice and 
research findings reported in this paper. The provision of clear guidance with respect to technical matters, the use of multiple channels of communication to convey key messages about the availability and value of the resource and demonstrations or 'tasters' are all of significance in this respect. In other words, what some would regard as the 'softer' aspects of technological developments should not go by default.

\section{References}

Clarke, R. \& Croft, P. (1998) Critical reading for the reflective practitioner: a guide for primary care (Boston, Butterworth-Heinemann).

Click and Go Video (2002) Fast forward to video streaming. Available online at: http://www.clickandgovideo.ac.uk/ (accessed 28 February 2005).

Digital Video Applications (2004) Digital video applications. Available online at: http:// library.open.ac.uk/waltonhall/diva/index.html (accessed 21 February 2005).

Fill, K. \& Ottewill, R. (2005) Sink or swim: maximising the potential of video streaming in higher education, Innovations in Education and Training International, forthcoming.

Green, S., Voegeli, D., Harrison, M., Phillips, J., Knowles, J., Weaver, M. \& Shephard, K. (2003) Evaluating the use of streaming video to support student learning in a first-year life sciences course for student nurses. Nurse Education Today, 23, 255-261.

JISC (2004) Technologies: V. Available online at: http://www.jisc.ac.uk/index.cfm?name= techwatch_resources_specific_v\#videostreaming (accessed 21 February 2005).

Laurillard, D, (2002) Rethinking university teaching (London, RoutledgeFalmer).

LIFESIGN (2002) Networked moving images for the life sciences. Available online at: www.Lifesign.ac.uk (accessed 9 November 2004).

Shephard, K. (2003) Questioning, promoting and evaluating the use of streaming video to support student learning, British fournal of Educational Technology, 34(3), 297-310.

Shephard, K., Ottewill, R., Phillips, P. \& Collier, R. (2003) From videocassette to video stream: issues involved in re-purposing an existing educational video, ALT-f, 11(2), 14-22.

Thornhill, S., Asensio, M. \& Young, C. (2002) Video streaming: a guide for educational development. Available online at: http://www2.umist.ac.uk/isd/lwt/clickgo/the_guide/Video_StreamingThe_Guide128bit.pdf (accessed 21 February 2005).

UK Libraries Plus (2005) UK Libraries Plus members $A-Z$ list. Available online at: http:// www.uklibrariesplus.ac.uk/memaz.htm (accessed 28 February 2005)

Zenios, M. (2002) The use of video streaming in higher education: a report on the evaluation of the Click and Go Video case studies and the educational benefits for learners. Available online at: http:// www.clickandgovideo.ac.uk/evaluation_casestudies.htm (accessed 1 March 2005). 